\title{
Analysis of the stress-strain state of the process pipeline to tank junction in case of subsidence
}

\author{
Aleksandr Tarasenko ${ }^{1}$, Petr Chepur ${ }^{1}$, and Alesya Gruchenkova ${ }^{2, *}$ \\ ${ }^{1}$ Industrial University of Tyumen, 625000 Volodarskogo Street 38, Russia \\ ${ }^{2}$ Surgut Oil and Gas Institute, Surgut, 628405 Entuziastov Street 38, Russia
}

\begin{abstract}
The article presents the developed finite element model of the emergency oil discharge system pipelines with a junction to the tank. Numerical modeling was carried out in the ANSYS software complex, with the help of which the model of the junction under consideration was created, considering the geometric and physical nonlinearity of the structure. A design model for the structure deformation is proposed in case the base subsidence develops. With the help of the tabulated function, it was possible to determine the value of subsidence at which critical stresses arise in the metal. Dependences of the maximum effective stresses in the metal structures of the wall to emergency discharge system pipeline junction on the RVS-20000 subsidence values are obtained. When the tank subsidence value is $144 \mathrm{~mm}$, the limiting state in the wall and the junction to the pipeline occurs and the metal passes into the state of developing plastic deformations.
\end{abstract}

\section{Introduction}

The works of the authors [1-9] study the influence of the base subsidence on the stressstrain state of the metal structures of large vertical steel tanks. However, in these studies, numerical models of tank deformations are considered without taking into account process pipelines and other elements of additional stiffness. However, the experience of operating VSTs and the data of long-term observations $[1,10,11]$ indicate that in order to accurately assess the stress state of the tank structure in the case of non-axisymmetric deformations caused by uneven base subsidence, stiffness of external connections from the connected equipment, pipelines and technological systems must be taken into account in numerical models.

In this paper, it is proposed to perform analysis of the impact of the emergency discharge pipeline on the stress state of the RVS-20000 (Figure 1) tank structure when the base subsidence develops.

To achieve this goal, it is necessary to perform numerical modeling of structures and components of the emergency oil discharge system based on the finite element model of the RVS-20000 tank, previously developed by the authors [12-16].

* Corresponding author: alesya2010-11@yandex.ru 


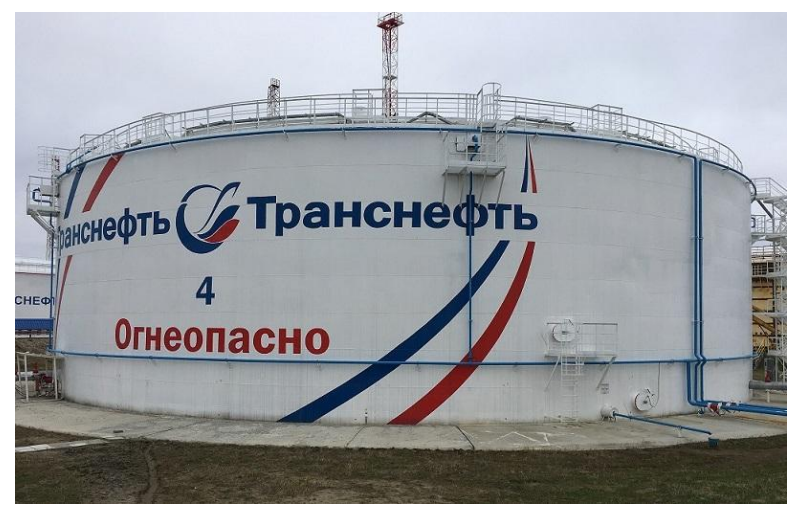

Fig. 1. General view of RVS-20000.

\section{Methods}

For modeling, the ANSYS software product [17, 18, 19] with the Static Structural calculation module was used, which allows solving non-axisymmetric deformation tasks of various structures considering physical and geometric nonlinearity.

The calculation model of RVS-20000 with the connectable system of pipelines of the emergency discharge system includes the following structures: U-shaped pipeline DU700, rigidly clamped from one end (the outlet of the underground pipeline to the day surface) and connected to the first belt of the VST wall through the tee at two points; at the pipelines to wall junctions, the design of reinforcing collars is taken into account; the model takes into account the contact interaction of the tee with the support - a separately standing reinforced concrete foundation; also, additional stiffening beam connections of the Ushaped pipeline with the VST wall are modeled, the type of the metal profile is the equilateral angle 100x10. All geometric parameters of the modeled VST designs correspond to the characteristics of the actually operated RVS-20000 tank No.6 at the LODS "Torgili".

The model of the emergency discharge assembly is generated by the shell finite elements - pipelines, bends, tee, reinforcing collars (SHELL181) and the beam ones connection angles of the pipeline fastening to the wall (BEAM188). Tank subsidence is set using the "displacement" function, which allows modeling the RVS-20000 subsidence along the contour by a predetermined value. Figure 2 shows the calculation model proposed by the authors.

To obtain the dependences of the SSS parameters on the tank subsidence value, it is necessary to investigate such a range of values of a given displacement (subsidence ), at which critical stresses corresponding to the yield strength characteristics of the 09G2C metal used in tank construction will appear.

When solving such a problem, the tabulated function of loading stages was used. The minimum value of subsidence was chosen equal to $5 \mathrm{~mm}$, while the estimated calculation showed that such a displacement value does not cause stresses over $30 \mathrm{MPa}$. Then, subsidence was incrementally increased in $10 \mathrm{~mm}$ steps and calculations were repeated, the purpose of which was to achieve critical deformation values (325 MPa for the 09G2S steel, in this case). 


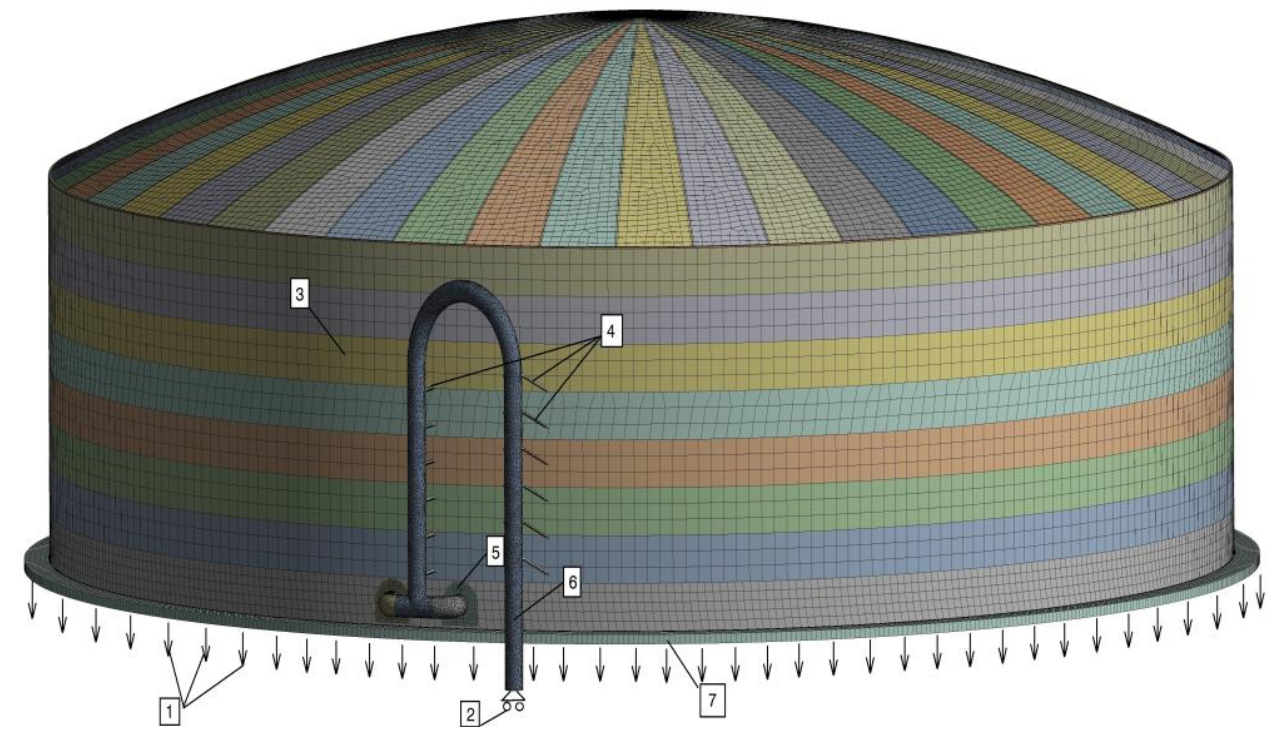

Fig. 2. Calculation model of the emergency discharge system and the RVS-20000 wall junction: 1 specified VST subsidence value; 2 - rigid fixing, 3 - wall sheets; 4 - contact areas; 5 - reinforcing collars; 6 - DU700 pipeline; 7 - ring foundation.

\section{Results and discussion}

The calculation was automatically interrupted at $150 \mathrm{~mm}$ subsidence, because in the welded joint of the reinforcing collar, wall and the pipeline junction, the effective equivalent stresses reached a value of $338 \mathrm{MPa}$. A refinement calculation showed that at a $144 \mathrm{~mm}$ subsidence value, a yield point of $325 \mathrm{MPa}$ was reached in the metal, after which plastic deformations of the metal structures began.

Figures 3-5 show distribution diagrams of the equivalent stresses and deformations of the metal structures when the $144 \mathrm{~mm}$ critical level of subsidence is reached.

From the results of strength analysis of the model in the ANSYS complex, the following features can be identified: the stress growth in the VST metal structures has a nature close to linear before reaching a yield point of $325 \mathrm{MPa}$; at RVS-20000 subsidence values greater than $10 \mathrm{~cm}$, the additional stiffening connections of the pipeline (equilateral angles) to the wall do not cause excessive stresses that could cause a violation of the technical condition of the VST (maximum stress at $150 \mathrm{~mm}$ subsidence - $167 \mathrm{MPa}$ ); the greatest danger is caused by welded joints of the pipeline and the wall with reinforcing collars, where the limiting state arises first of all at the above-mentioned subsidence values.

Figure 6 is a graph showing the dependence of the value of the effective equivalent stresses in the metal structures of the emergency oil discharge system pipelines to wall junction on the RVS-20000 subsidence level. 


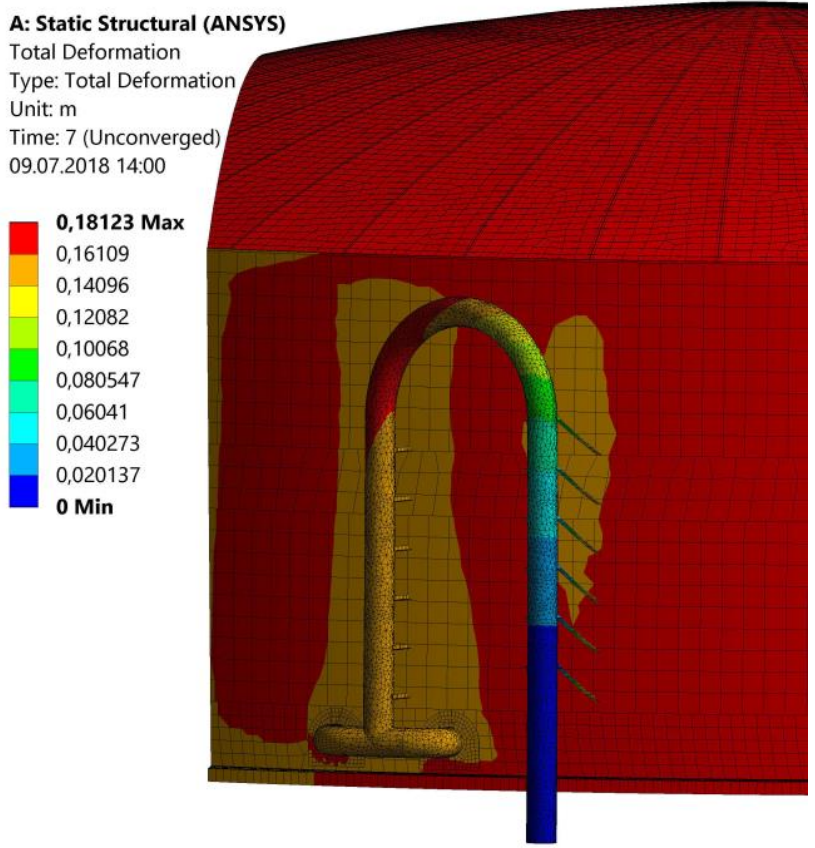

Fig. 3. Deformations of the RVS-20000 metal structures in the area of the emergency oil discharge system pipelines to wall junction.

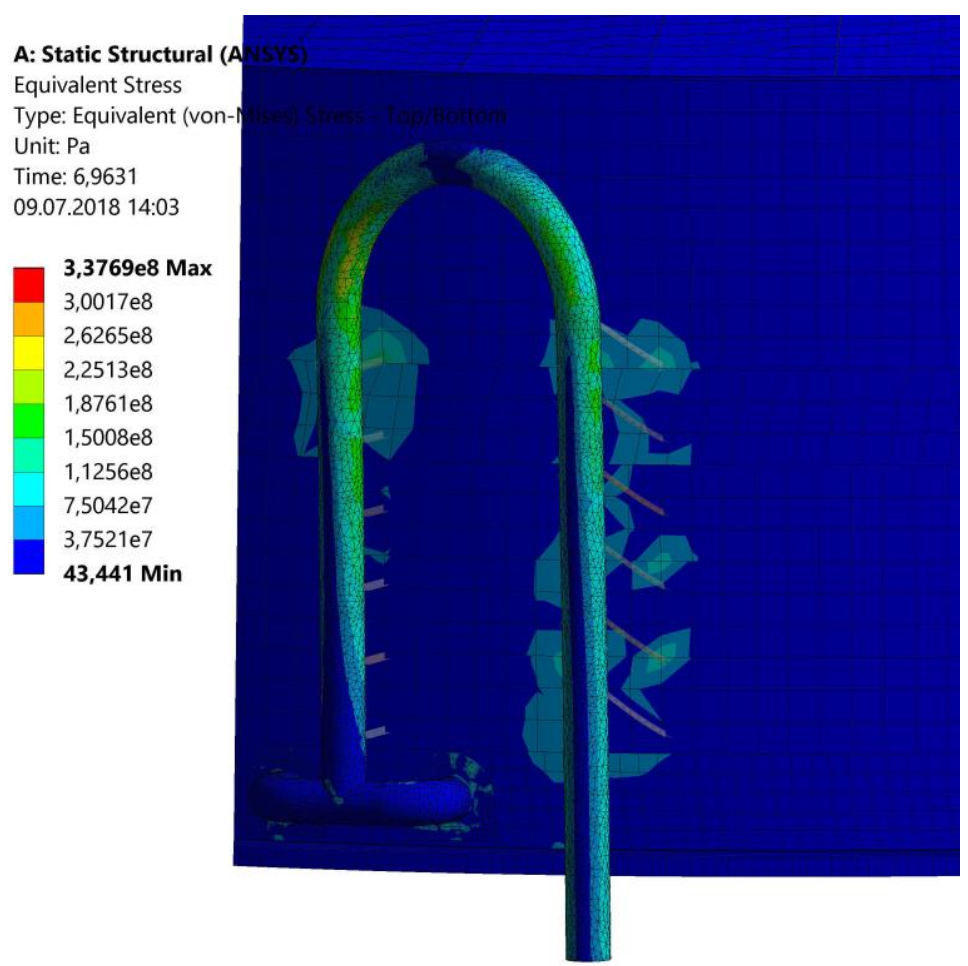

Fig. 4. Effective equivalent stresses in the RVS-20000 metal structures in the area of the emergency oil discharge system pipelines to wall junction. 


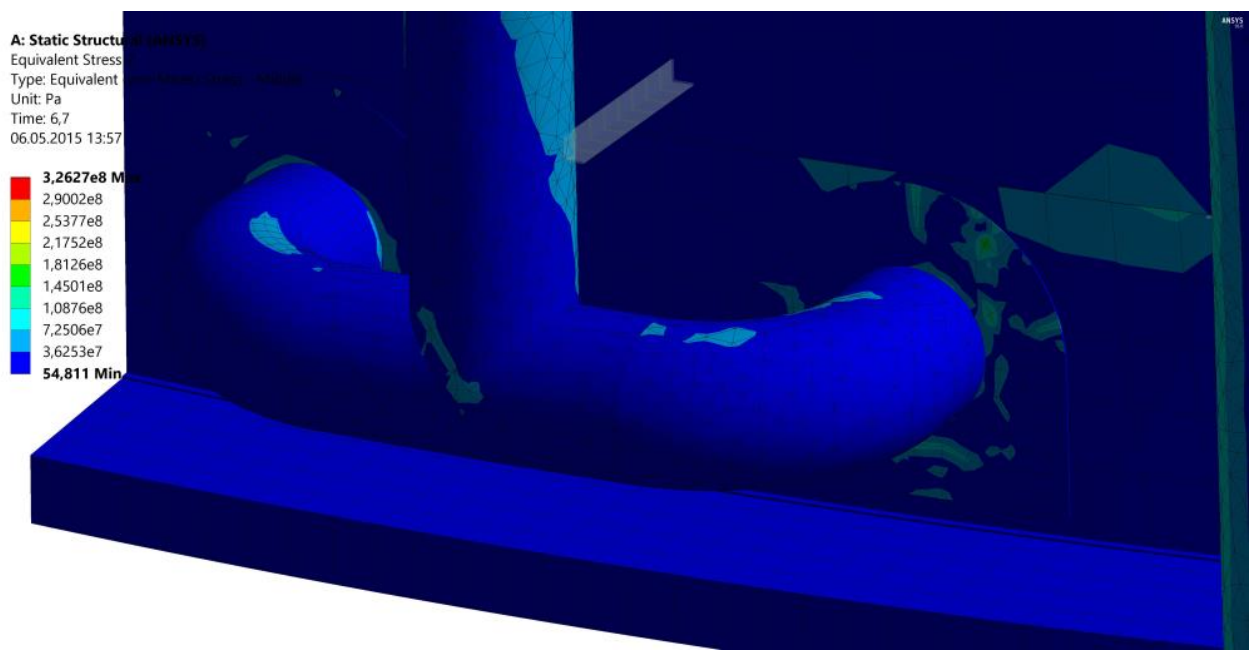

Fig. 5. Effective equivalent stresses in the RVS-20000 reinforcing collars.

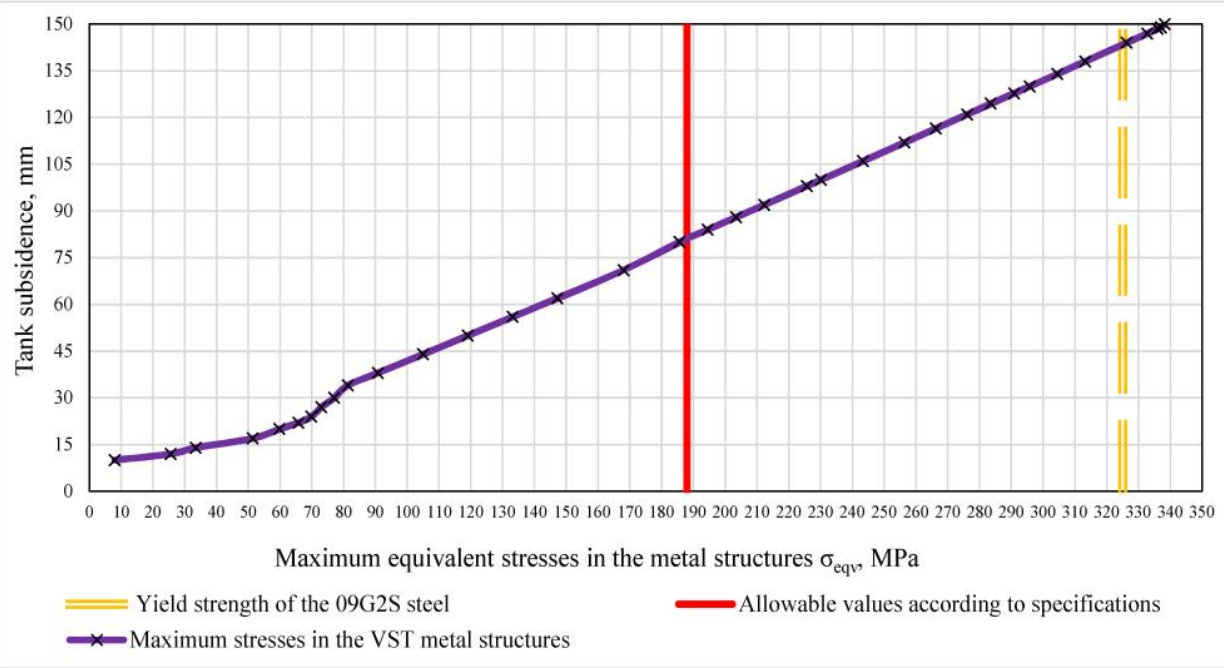

Fig. 6. Dependence of the effective equivalent stresses in the metal structures of the emergency oil discharge system pipelines to wall junction on the RVS-20000 subsidence level.

\section{Conclusions}

In the work, the authors developed a finite element model of the emergency oil discharge system pipelines with a junction to the RVS-20000 tank. Numerical modeling was carried out in the ANSYS software complex, with the help of which the model of the junction under consideration was created, considering the geometric and physical nonlinearity of the structure. A design model for the structure deformation is proposed in case the base subsidence develops. A change in the SSS level is caused by the elements of additional stiffness of the emergency discharge system pipelines, which has a welded contact with the wall and a rigid fixing of the free end at the point of transition underground.

With the help of the tabulated function, it was possible to determine the value of subsidence at which critical stresses arise in the metal. Based on the results of calculations, dependences of the maximum effective stresses in the metal structures of the wall to 
emergency discharge system pipeline junction on the RVS-20000 subsidence values were obtained. When subsidence is greater than $80 \mathrm{~mm}$, effective equivalent stresses in the pipeline to tank wall and collar junction exceed the maximum allowable value according to specifications - $188 \mathrm{MPa}$ (the value of which is calculated in [7] for this RVS-20000). When the tank subsidence value is $144 \mathrm{~mm}$, the limiting state in the wall and the junction to the pipeline occurs, while the effective stresses exceed $325 \mathrm{MPa}$ and the metal passes into the state of developing plastic deformations.

\section{Acknowledgments}

The paper was prepared within the implementation of the basic part of the government task for the project № 7.7858.2017/BP: "Development of the scientific principles of the techniques for determining the stress-strain state of the large-sized storage tanks during the differential settlement of the substructures and foundations".

\section{References}

1. A.S. Gorelov, Neodnorodnye gruntovye osnovaniya $i$ ikh vliyanie na rabotu vertikal'nykh stal'nykh rezervuarov (Nedra, Saint Petersburg, 2009)

2. A.A. Tarasenko, P.V. Chepur, S.V. Chirkov, Oil Indust. 3, 123-125 (2016)

3. Y. Guan, A.A. Tarsenko, S. Huang, P.V. Chepur, R. Zhang, World Inf. on Earthquake Eng. 32(1), 219-227 (2016)

4. A.A. Tarasenko, P.V. Chepur, Y. Guan, Oil Indust. 4, 134-136 (2016)

5. A.A. Tarasenko, P.V. Chepur, Soil Mech. and Found. Eng. 53(4), 238-243 (2016)

6. A.A. Tarasenko, A.A. Gruchenkova, M.A. Tarasenko, Oil Indust. 8, 132-135 (2016)

7. A. Tarasenko, A. Gruchenkova, P. Chepur, Proc. Eng. 165, 1125-1131 (2016)

8. A. Gruchenkova, A. Tarasenko, P. Chepur, D. Tarasenko, AIP Conf. Proc. 1800, 040019 (2017)

9. A. Tarasenko, P. Chepur, A. Gruchenkova, MATEC Web of Conf. 73, 01018 (2016)

10. A.A. Tarasenko, P.A. Konovalov, F.F. Zekhniev, P.V. Chepur, D.A. Tarasenko, Soil Mech. and Found. Eng. 53(6), 405-411 (2017)

11. A. Tarasenko, P. Chepur, A. Gruchenkova, AIP Conf. Proc. 1772, 060011 (2016)

12. P.V. Chepur, A.A. Tarasenko, A.A. Gruchenkova, J. of Phys.: Conf. Series 1015, 032049 (2018)

13. A. Tarasenko, P. Chepur, A. Gruchenkova, AISC 692, 936-943 (2018)

14. S. Chirkov, A. Tarasenko, P. Chepur, IOP Conf. Series: Earth and Environ. Sci. 90, 012102 (2017)

15. A.A. Tarasenko, P.V. Chepur, A.A. Gruchenkova, J. of Phys.: Conf. Series 1015, 032047 (2018)

16. A. Tarasenko, P. Chepur, S. Chirkov, AIP Conf. Proc. 1772, 060010 (2016)

17. V.A. Bruyaka, V.G. Fokin, E.A. Soldusova, et.al. Inzhenernyy analiz $v$ ANSYS Workbench (Samara state technical University, Samara, 2010)

18. G.E. Korobkov, R.M. Zaripov, I.A. Shammazov, Chislennoe modelirovanie napryazhenno-deformirovannogo sostoyaniya $i$ ustoychivosti truboprovodov $i$ rezervuarov v oslozhnennykh usloviyakh ekspluatatsii (Nedra, Saint Petersburg, 2009)

19. A.V. Beloborodov, Vestnik of the Ural Fed. Univ. 1, 78-81 (2005) 